\title{
Improving Cape Verde's Digital Governance Strategy Formulation Process
}

\author{
Wagner S. Araujo \\ United Nations University Operating \\ Unit on Policy-Driven Electronic \\ Governance (UNU-EGOV) and \\ Algoritmi Centre, University of \\ Minho, Portugal \\ wagner.s.araujo@unu.edu
}

\author{
Mário G. Cardoso \\ Government of Cabo Verde \\ mario.g.cardoso@mf.gov.cv
}

\author{
João Cruz \\ Government of Cabo Verde \\ jcruz@casadocidadao.gov.cv
}

\begin{abstract}
Abstract: The Digital Governance Strategy formulation process in Cape Verde, an archipelagic African country with a remarkable EGOV background, was recently carried on in a partnership between the Government Agencies, the Academy, Private Sector Entities, and Civil Society Personalities. The endeavor resulted in a strategic official document, approved in technical and political instances, including the National Committee for the Digital Strategy. As a first step, the initial strategy formulation process has been improved, generating a new one, composed of five delimited stages: Diagnosis and Context Analysis; Definition of the Vision; Definition of Intervention Areas; Definition of the Objectives; and Definition of Structuring Pillars. After a period of six months of teamwork, supported by the Action Research Approach, it resulted in the new Cape Verde strategy for the 2021-2023 period. This paper highlights the characteristics of the improved process, which can benefit other countries due to its consistency, cohesiveness, and reusability potential.
\end{abstract}

\section{CCS CONCEPTS}

-Applied computing $\rightarrow$ Computers in other domains; Computing in government; E-government.

ACM Reference Format:

Wagner S. Araujo, Mário G. Cardoso, and João Cruz. 2021. Improving Cape Verde's Digital Governance Strategy Formulation Process. In 14th International Conference on Theory and Practice of Electronic Governance (ICEGOV 2021), October 06-08, 2021, Athens, Greece. ACM, New York, NY, USA, 3 pages. https://doi.org/10.1145/3494193.3494312

\section{INTRODUCTION}

Cape Verde is an archipelagic country with 10 islands in the middle of the Atlantic Ocean, on the western coast of Africa, which have been investing heavily in the EGOV development since 1998. The country attained in 2020 the High-Level Group in the Electronic Government Development Index according to the UN EGovernment Survey [1]. Cape Verde achieved considerable results,

Publication rights licensed to ACM. ACM acknowledges that this contribution was authored or co-authored by an employee, contractor or affiliate of a national government. As such, the Government retains a nonexclusive, royalty-free right to publish or reproduce this article, or to allow others to do so, for Government purposes only. ICEGOV 2021, October 06-08, 2021, Athens, Greece

(c) 2021 Copyright held by the owner/author(s). Publication rights licensed to ACM. ACM ISBN 978-1-4503-9011-8/21/10 . \$15.00

https://doi.org/10.1145/3494193.3494312 which includes the existence of a National Digital ID, a fully operational interoperability framework, a typical digital one-stop-shop, and dedicated online services to the diaspora community, something important to a country that has most citizens living abroad.

Currently, the country's digital challenges are related to the establishment of an integrated governance model to aim higher milestones, including digital inclusion, digital literacy, and the development of public sector human resources in digital skills. Additional challenges are proper ICT regulation, the consolidation of interoperability framework, improvement of the one-stop-shop platform and the nation's cybersecurity, as well as the enhancement of the public administration and government transparency through the full implementation of open government and open data concepts [2], [3]. The IX Legislature Government of Cape Verde, aiming the accomplishment of an integrated and mobile government, recently created the National Committee for Digital Strategy and defined several initiatives to accelerate the digital transformation of the public administration through the improvement on Digital Governance, alongside the duty for improvement of the Digital Economy ecosystem with investments on better internet access, technological capacitation, and innovation. Therefore, the need for a well-defined strategy for Digital Governance was considered a must in consideration of all the challenges faced in the public services provided for citizens and business, and internally in the public sector.

This paper aims to share Cape Verde's experience on the new Digital Governance Strategy for the period between 2021 to 2023, a process that occurred between July and December 2020, ending with the submission to the Council of Ministers after the approval by the National Committee for Digital Strategy, in February 2021. The process was carried out in a partnership between the Cape Verde Government and the Academy, which resulted in a team with two Cape Verde high-level public officials and three senior EGOV specialists with scientific and professional backgrounds. This partnership was necessary to assure the systematization and improvement of the process until the complete formulation of the strategy.

\section{BACKGROUND}

EGOV strategies are a top-level document that addresses strategic directions, goals, components, principles, and implementation guidelines [4]. International institutions seem to reinforce the importance of this document, for example, in world summits on the Information Society conducted by the United Nations [5]. In fact, 


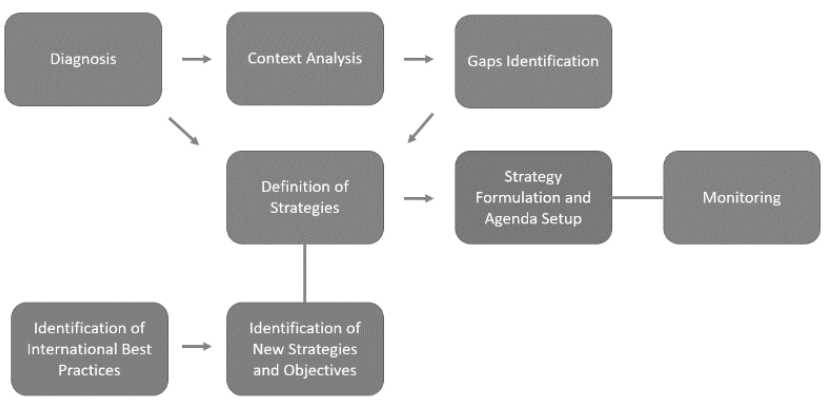

Figure 1: Initial method used for the Cape Verde Digital Governance Strategy formulation

from 193 Member States of the UN, 151 have digital strategies today [1].

The strategy should encompass the multiple and diverse purposes of Digital Governance, such as improve government performance and generating more cost-effective government operations; increase efficiency and effectiveness of electronic public service delivery; mitigate information asymmetry in the society; strengthen government interaction and relationship with several stakeholders; enhance citizens' participation in decision-making process; and promote open, transparent, and accountable government and societies [6]. To achieve these purposes, countries develop national strategies to rigorous address their efforts, considering aspects such as the political, economic, technological, social, cultural, and legal status of the country [7].

Cape Verde starts the process of formulation of its strategy with the method shown in Figure 1. Although containing typical stages of the strategy formulation process, country policymakers identified the need to search for specialized support. Expectations included access to scientific knowledge and experienced background to support the strategy formulation, as well as its institutionalization in the government. Action Research Approach has been chosen to support this partnership, mainly because this methodology synergistically and holistically associates research and practice and can produce highly relevant research results due it is grounded in practical action solving an immediate problem situation while carefully informing theory [8]. To proceed the evaluation phase of the research approach, four interviews with two collaborative researchers and two practitioners has been proceed, followed by a content analysis to assess the outcomes.

\section{RESULTS: THE NEW CAPE VERDE'S DIGITAL GOVERNANCE STRATEGY}

After a previous analysis of the ongoing process, the following interventions have been done in the initial process:

i) Five of the previous stages have been condensed into one, because of the similarities in diagnosis purpose, differing only on the type of information used: Diagnosis, Situational Analysis, Identification of Gaps, Survey of Best International Practices, Identification of Emerging Strategies. The new stage has been named Diagnosis and Context Analysis; ii) A new stage, Definition of the Vision, has been created. It is an important step in the strategy

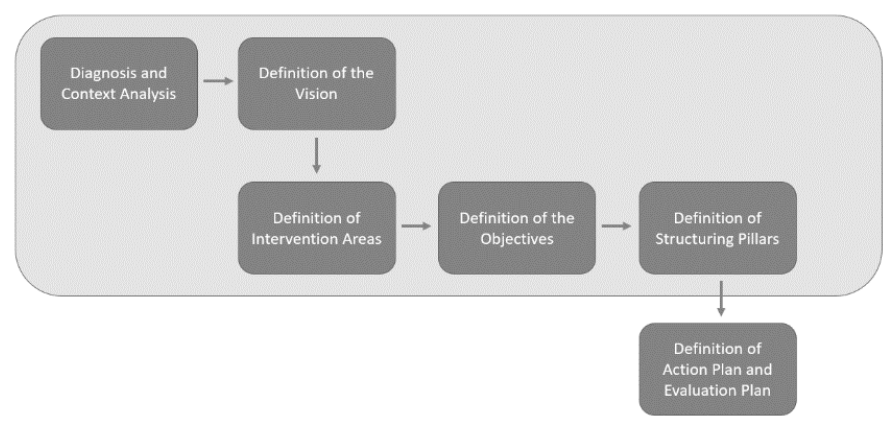

Figure 2: The new process of Digital Governance Strategy Formulation in Cape Verde

formulation process because the output vision will framework all other components of the strategy. For example, all strategic objectives should collaborate to reach the vision statement; iii) The stage Definition of Strategies has been split into three others: Definition of Intervention Areas, Definition of the Objectives, and Definition of Structuring Pillars. This split was necessary because inputs and outputs differ in each stage and maintaining them together would risk the consistency and cohesiveness of the process; iv) The Monitoring stage has moved to a process apart. This occurred because the monitoring phase depends on the formulation of an Action Plan, a document that should derive from the Strategy. A strategy document contains the choices the country defines. The Action Plan focuses on the necessary resources to implement these choices, and when they will be available. The Action Plan and Evaluation Plan are pre-conditions for monitoring purposes. They are expected to be constructed immediately after and based on strategic choices; v) All stages inputs and outputs were reviewed to assure that each stage provides consistent outputs to be consumed by the next ones. Therefore, all information transiting in the process should flow from previous and provider stages to subsequent and consumer stages. This brought consistency and cohesiveness to the new process; vi) The new strategy formulation process used as theoretical background previous scientific work [4], [7].

The final Strategy Formulation Process is composed of five stages and is depicted in Figure 2

The Diagnosis and Context Analysis collected many sources of information regarding national and international context. For the national context, inputs were the history of Cape Verde in EGOV, the regulatory framework, former and current government strategies, a list of former and current international partnerships, the result of a SWOT workshop with multiple stakeholders, a series of interviews with key actors, the government ICT infrastructure inventory, and the public services inventory. The SWOT workshop and the set of interviews involved 14 ministries, seven public administration entities, 10 actors from the civil society and private sector, and one from the academia / public university. To compose the international context, inputs were the international indexes data, such as the United Nations EGOV Development Index and E-Participation Index, the World Bank Ease of Doing Business Index, the World Economic Forum Global Competitiveness Index, 
the International Telecommunication Union Global Cybersecurity Index Report, and a list of countries of reference to Cape Verde. This stage outputs a national context analysis including the SWOT analysis, a list of intersections between current government strategies and Digital Governance purposes, a list of online public services expectations, constructed based on the analysis of public service inventory analysis, a report on gaps in government infrastructure, the analysis of international rankings country results; a list of relevant international rankings characteristics, and a countries-of-reference benchmarking report. All subsequent stages receive as inputs the outputs produced in this stage, some of them with more emphasis depending on the stage purpose. All used inputs maintained the respective traceability to their origins, to assure the process consistency and cohesiveness.

The Vision has been established by a single and strong statement: "A digital Cape Verde, an agile, capable, resilient, reliable and transparent State, closer to citizens and business in all life events.”. Intervention Areas and Objectives have been defined to contribute to reaching the established vision. It has been defined 12 objectives in Digital Public Services area; 9 objectives in Digitalization and Simplification of Administrative Procedures area; 12 in Access and Availability of information; 4 in Integration and Interoperability; 6 in Infrastructure and Security; 11 objectives in Technology; 14 objectives in Legislation; 5 in Human Resources Literacy; and 7 objectives in Governance area.

The Structuring Pillars, shared and enabler structures offering support to all the pre-defined objectives, have been classified into three categories: Administrative, with 11 structuring pillars; Legislative, with 18; and Technological with 27. Examples of them are, respectively, a National Program for Administrative Simplification; a Decree to implement the National Directorate for Administrative Modernization; and a new Electronic Authentication Platform.

\section{CONCLUSION}

This paper described the evolution of Cape Verde's Digital Governance Strategy formulation process, resulting in a more consistent and cohesive one. These characteristics have been confirmed by interviews with government stakeholders and policymakers, as part of the evaluation phase of the Action Research approach. The interviewee remarked as positive aspects the possibility to involve multiple stakeholders and the amplitude of the diagnosis phase. The repositioning of the Action Plan and Evaluation Plan as a separate stage has been pointed as an aspect to fine-tune, although recognizing the complexity to define the allocation of resources and establish mature deadlines during the process of strategy formulation. The new process has been also considered flexible by the interviewees, suggesting the potential reuse possibility by other countries. Finally, the process effectively produced the new Cape Verde Digital Governance Strategy for the 2021 - 2023 period, formally approved by the higher technical political instance of the country, the National Committee for Digital Strategy.

\section{REFERENCES}

[1] Department of Economic and Social Affairs, E-Government Survey 2020 - Digital Government in the Decade of Action for Sustainable Development: With addendum on COVID-19 Response. 2020.

[2] World Bank Group, "República de Cabo Verde Ajustando o Modelo de Desenvolvimento para Revitalizar o Crescimento e Fortalecer a Inclusão Social," p. 123, 2018.

[3] OECD, "Promoting the Digital Transformation of African Portuguese-Speaking Countries and Timor-Leste," p. 136, 2018.

[4] A. Rabaiah and E. Vandijck, "A Strategic Framework of eGovernment: Generic and Best Practice," Electron. J. e-Government, vol. 7, no. 3, pp. 241-258, 2009.

[5] R. Sandoval-Almazán, L. F. Luna-Reyes, D. E. Luna-Reyes, J. R. Gil-Garcia, G. PuronCid, and S. Picazo-Vela, "Developing a digital government strategy for public value creation," in Public Administration and Information Technology, vol. 16, 2017, pp. $7-20$.

[6] A. Alarabiat, D. Soares, L. Ferreira, and F. De Sá-Soares, "Analyzing e-governance assessment initiatives: An exploratory study," ACM Int. Conf. Proceeding Ser., no. ii, 2018.

[7] C. G. Mkude and M. A. Wimmer, "Strategic framework for designing e-government in developing countries," in Lecture Notes in Computer Science (including subseries Lecture Notes in Artificial Intelligence and Lecture Notes in Bioinformatics), 2013, vol. 8074 LNCS, pp. 148-162.

[8] R. L. Baskerville, "Investigating Information Systems with Action Research," Commun. Assoc. Inf. Syst., vol. 2, no. October 1999. 